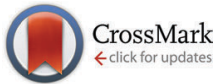

Cite this: Phys. Chem. Chem. Phys., 2015, 17, 22259

Received 11th May 2015 Accepted 29th July 2015 DOI: $10.1039 / c 5 c p 02711 \mathrm{j}$

www.rsc.org/pccp

\title{
Unusual Mn coordination and redox chemistry in the high capacity borate cathode $\mathrm{Li}_{7} \mathrm{Mn}\left(\mathrm{BO}_{3}\right)_{3}^{\dagger}$
}

\author{
Julian Roos, ${ }^{a b}$ Christopher Eames, ${ }^{\text {a }}$ Stephen M. Wood, ${ }^{a}$ Alexander Whiteside ${ }^{\mathrm{ac}}$ and \\ M. Saiful Islam*a
}

\begin{abstract}
The recently discovered lithium-rich cathode material $\mathrm{Li}_{7} \mathrm{Mn}\left(\mathrm{BO}_{3}\right)_{3}$ has a high theoretical capacity and an unusual tetrahedral $\mathrm{Mn}^{2+}$ coordination. Atomistic simulation and density functional theory (DFT) techniques are employed to provide insights into the defect and redox chemistry, the structural changes upon lithium extraction and the mechanisms of lithium ion diffusion. The most favourable intrinsic defects are Li/Mn anti-site pairs, where $\mathrm{Li}$ and $\mathrm{Mn}$ ions occupy interchanged positions, and Li Frenkel defects. DFT calculations reproduce the experimental cell voltage and confirm the presence of the unusually high $\mathrm{Mn}^{\vee}$ redox state, which corresponds to a theoretical capacity of nearly $288 \mathrm{~mA} \mathrm{~h} \mathrm{~g}$. The ability to reach the high manganese oxidation state is related to both the initial tetrahedral coordination of $\mathrm{Mn}$ and the observed distortion/tilting of the $\mathrm{BO}_{3}$ units to accommodate the contraction of the $\mathrm{Mn}-\mathrm{O}$ bonds upon oxidation. Molecular dynamics (MD) simulations indicate fast three-dimensional lithium diffusion in line with the good rate performance observed.
\end{abstract}

\section{Introduction}

The implementation of layered $\mathrm{LiCoO}_{2}$ as the cathode in rechargeable lithium-ion batteries heralded the revolution in portable electronics. Since then, the search for alternative cathode materials has generated considerable research activity, ${ }^{1-6}$ particularly for large-scale applications such as electric vehicles or grid storage. Significant interest has focused on materials such as olivinestructured $\mathrm{LiFePO}_{4},{ }^{1-5,7}$ where the strong binding in the polyanion unit leads to a stable framework with long cycle life and high safety. Further polyanionic framework systems have been explored, and several promising candidates have been identified, including: $\mathrm{Li}_{2} \mathrm{MSiO}_{4}{ }^{8,9} \mathrm{LiMSO}_{4} \mathrm{~F},{ }^{10-12} \mathrm{Li}_{2} \mathrm{MPO}_{4} \mathrm{~F},{ }^{13} \mathrm{Li}_{2} \mathrm{MP}_{2} \mathrm{O}_{7},{ }^{14}$ and $\mathrm{Li}_{2} \mathrm{M}\left(\mathrm{SO}_{4}\right)_{2}{ }^{15,16}(\mathrm{M}=\mathrm{Fe}, \mathrm{Mn}, \mathrm{Ni})$.

The borate family of cathode materials $\mathrm{LiMBO}_{3}{ }^{17-25}$ offer high capacities due to the low mass of the borate polyanion. Yamada et $a .^{17}$ demonstrated capacities of about $190 \mathrm{~mA} \mathrm{~h} \mathrm{~g}{ }^{-1}$ for the monoborate system $\mathrm{LiFeBO}_{3}$ (theoretical capacity $220 \mathrm{~mA} \mathrm{~h} \mathrm{~g}^{-1}$ ), which is considerable compared to $\mathrm{LiCoO}_{2}$ and $\mathrm{LiFePO}_{4}$ with theoretical capacities of 272 and $170 \mathrm{~mA} \mathrm{~h} \mathrm{~g}{ }^{-1}$ respectively. ${ }^{7,26}$ More recently, the new borate system $\mathrm{Li}_{7} \mathrm{Mn}\left(\mathrm{BO}_{3}\right)_{3}$ with a rare tetrahedral $\mathrm{Mn}$ coordination environment was discovered ${ }^{27}$

\footnotetext{
${ }^{a}$ Department of Chemistry, University of Bath, Bath, BA2 7AY, UK. E-mail:m.s.islam@bath.ac.uk, c.eames@bath.ac.uk

${ }^{b}$ Technical University of Munich, 85748 Garching/Munich, Germany

${ }^{c}$ Department of Chemistry, University of Cambridge, Cambridge, CB2 1TN, UK

$\dagger$ Electronic supplementary information (ESI) available. See DOI: 10.1039/ c5cp02711j
}

(Fig. 1), which displays an extremely large theoretical capacity of $\approx 288 \mathrm{~mA} \mathrm{~h} \mathrm{~g}^{-1}$ upon extraction of 3 lithium ions per formula unit. After preparation of nano-composite electrodes, the material was found to deliver first charge and discharge capacities of about 280 and $154 \mathrm{~mA} \mathrm{~h} \mathrm{~g}^{-1}$ respectively, and was subsequently cycled in the range $4.7-1.7 \mathrm{~V}$ at $10 \mathrm{~mA} \mathrm{~g}^{-1} \mathrm{~h}^{-1}$ with moderate capacity losses. ${ }^{27}$ The first charge capacity corresponds to an unusually high oxidation of manganese from $\mathrm{Mn}^{\mathrm{II}}$ up to $\mathrm{Mn}^{\mathrm{V}}$.

However, such redox behaviour in this system is not fully understood. Indeed, knowledge of the fundamental solid-state properties at the atomic scale is required to better understand the factors influencing the electrochemical behaviour of $\mathrm{Li}_{7} \mathrm{Mn}\left(\mathrm{BO}_{3}\right)_{3}$.

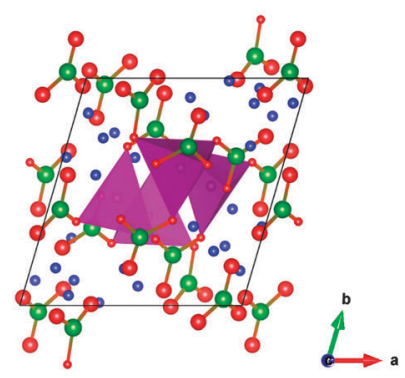

(a)

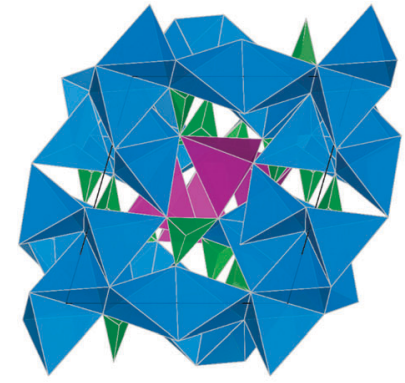

(b)
Fig. 1 Two representations of the observed crystal structure of $\mathrm{Li}_{7} \mathrm{Mn}_{\mathrm{n}}\left(\mathrm{BO}_{3}\right)_{3}$ seen along [001]; Key: O-red, B-green, Li-blue, Mn-violet. (a) columns of $\mathrm{MnO}_{4}$ tetrahedra expanding along the $c$-axis. (b) complex framework of $\mathrm{LiO}_{x}$ $(x=3,4,5)$ polyhedra (blue) that encloses the $\mathrm{MnO}_{4}$ columns and is interconnected through trigonal $\mathrm{BO}_{3}$ units (green). 
In this study, well-established atomistic simulation ${ }^{28-30}$ and density functional theory ${ }^{31-37}$ (DFT) techniques are employed to examine key issues related to point defects, Mn redox chemistry and lithium diffusion. This computational study will provide useful insights into this promising manganese borate system, and may trigger renewed interest into the related class of lithiumrich electrode materials.

\section{Methodology}

Since this study employs well-established atomistic and DFT techniques, which are described in detail elsewhere, ${ }^{4,36,37}$ only a general outline will be given here. The interatomic potentials comprise a long-range Coulombic term and a short-range component representing Pauli repulsion and van der Waals interactions, represented by Buckingham potentials ${ }^{28}$ of the form

$$
\Phi_{i j}\left(r_{i j}\right)=A_{i j} \exp \left(-\frac{r_{i j}}{\rho_{i j}}\right)-\frac{C_{i j}}{r_{i j}{ }^{6}}
$$

where $r_{i j}$ is the distance between interacting species $i$ and $j$, and the exact shape of the potential is determined by potential parameters $A, \rho$ and $C$. Structure optimisation and defect energy calculations were performed using the GULP $\operatorname{code}^{38}$ (v4.0). Defect energies were calculated using the Mott-Littleton scheme, ${ }^{39}$ where the lattice is partitioned into two regions, with ions located in an inner sphere being relaxed individually, whilst the outer region is treated by quasi-continuum approaches.

Lithium diffusion at finite temperature was modelled using molecular dynamics (MD) with DL_POLY ${ }^{40}$ (v4.05). An $8 \times 7 \times 6$ supercell, containing 25939 atoms, was employed. 10\% lithium vacancies were introduced at random to give a composition of $\mathrm{Li}_{6.3} \mathrm{Mn}\left(\mathrm{BO}_{3}\right)_{3}$. To maintain charge neutrality, a corresponding excess charge was distributed across all the manganese ions. The system was allowed to equilibrate for $1 \mathrm{~ns}$, with the main production runs performed with a 2 fs time step for almost $1 \mathrm{~ns}$. The calculations were conducted at temperatures in the range of $325-1025 \mathrm{~K}$ at intervals of $100 \mathrm{~K}$ using the NPT ensemble with a Berendsen thermostat. ${ }^{41}$ It is worth noting that such large supercells and long time-scales are not yet accessible by ab initio methods. Such potentials-based MD methods are well established in the simulation of ion diffusion in lithium battery materials. ${ }^{42-50}$

DFT calculations used the plane wave code VASP $^{51}$ (v5.3.5). The basis set was converged against the stress, instead of the forces, due to its higher sensitivity to an under-converged basis set. A cutoff energy of $800 \mathrm{eV}$ with a $k$-point mesh density larger than $0.04 \AA^{-1}$ was required to adequately converge the stress $\left(3 \times 3 \times 3\right.$ grid). PAW pseudopotentials ${ }^{52,53}$ and the PBEsol exchange-correlation functional ${ }^{54,55}$ were used. Calculations of various spin configurations found the ferromagnetic state to be favourable. To account for the strong correlation effects associated with the manganese d-electrons, a DFT $+\mathrm{U}$ methodology was used, with an effective Hubbard $U_{\text {eff }}=U-J=5.1 \mathrm{eV}(J=1.0 \mathrm{eV})$; this value is in agreement with previous theoretical studies of Mn-based cathode materials. ${ }^{56}$
DFT-based methods are well-established in examining lithium insertion/extraction properties of electrode materials, ${ }^{4,32}$ and have been successfully applied to predict trends in cell voltages. Upon deriving the correct delithiated structure, the average open circuit voltage can be calculated using:

$$
V=\frac{\varepsilon\left\{\mathrm{Li}_{7} \mathrm{Mn}\left(\mathrm{BO}_{3}\right)_{3}\right\}-\varepsilon\left\{\mathrm{Li}_{x} \mathrm{Mn}\left(\mathrm{BO}_{3}\right)_{3}\right\}-\{7-x\} \mu\{\mathrm{Li}\}}{7-x}
$$

where $\varepsilon\{Y\}$ is the total energy of $Y$ and $(7-x)$ is the amount of lithium atoms that are extracted per formula unit. In this study, three lithium atoms per formula unit have been removed to probe the delithiated structure $\mathrm{Li}_{4} \mathrm{Mn}\left(\mathrm{BO}_{3}\right)_{3}$. Several thousand possible ordering schemes for the Li vacancies were compared by performing interatomic potentials based structural optimisation on each configuration. The lowest energy structure obtained in this way was then optimised again using DFT to obtain the total energy used in eqn (2). Bulk lithium metal was used to determine the chemical potential of lithium $\mu\{\mathrm{Li}\}$, which is standard practice for cell voltage calculations.

\section{Results and discussion}

\subsection{Structure and intrinsic defect chemistry}

The triclinic $\mathrm{Li}_{7} \mathrm{Mn}\left(\mathrm{BO}_{3}\right)_{3}$ compound has previously been presented as a new structure type of space group $\bar{P},{ }^{27}$ and contains $\mathrm{Mn}^{2+}$ species in an unusual tetrahedral coordination environment. The lithium ions sit inside a range of different $\mathrm{LiO}_{x}$ polyhedra with $x=3,4,5$. The structure (Fig. 1) comprises pillars of $\mathrm{MnO}_{4}$ tetrahedra linked via borate groups and extending along the $c$-axis. Around these pillars expands a complex framework of edge- and vertex-sharing lithium polyhedra, enclosing additional borate units.

The starting point of the computer modelling study was to reproduce the experimentally observed crystal structure. The interatomic potential parameters used in this work are presented in Table 1. A direct comparison of the calculated and experimental unit cell parameters is presented in Table 2, which shows deviations from experiment within $3 \%$ and in most cases much less. There were several structural complexities to be dealt with while developing the potential model. The first is a lithium split site, ${ }^{27}$ which has to be modelled explicitly in the simulation, removing the inversion centre. Another challenge was posed by the wide range of individual boronand lithium-oxygen bond lengths $(d(\mathrm{~B}-\mathrm{O})=1.31-1.43 \AA, d(\mathrm{Li}-\mathrm{O})=$ 1.87-2.21 A). ${ }^{27}$ Despite the complexity, the potentials-based and DFT simulations were able to reproduce the observed crystal structure.

Table 1 Short-range Buckingham potential parameters for $\mathrm{Li}_{7} \mathrm{Mn}\left(\mathrm{BO}_{3}\right)_{3}$

\begin{tabular}{lllc}
\hline Interaction & $A(\mathrm{eV})$ & $\rho(\AA)$ & $C\left(\mathrm{eV} \AA^{6}\right)$ \\
\hline $\mathrm{Li}^{+}-\mathrm{O}^{2-}$ & 638.712146 & 0.290560 & 0.00 \\
$\mathrm{Mn}^{2+}-\mathrm{O}^{2-}$ & 2580.723796 & 0.277521 & 0.00 \\
$\mathrm{~B}^{3+}-\mathrm{O}^{2-}$ & 539.797394 & 0.340031 & 0.00 \\
$\mathrm{O}^{2-}-\mathrm{O}^{2-}$ & 22764.3 & 0.149 & 46.94
\end{tabular}


Table 2 Comparison of calculated and experimental ${ }^{27}$ unit cell parameters and mean bond lengths of $\mathrm{Li}_{7} \mathrm{Mn}\left(\mathrm{BO}_{3}\right)_{3}$

\begin{tabular}{llll}
\hline & Expt. & Calc. (potentials) & Calc. (DFT) \\
\hline$a / \AA$ & 8.3234 & 8.2814 & 8.3015 \\
$b / \AA$ & 9.1952 & 9.4215 & 9.1935 \\
$c / \AA$ & 11.248 & 11.539 & 11.216 \\
$\alpha /^{\circ}$ & 71.495 & 69.926 & 71.639 \\
$\beta /{ }^{\circ}$ & 79.525 & 79.953 & 79.686 \\
$\gamma /{ }^{\circ}$ & 71.368 & 71.193 & 71.400 \\
$\mathrm{Li}-\mathrm{O} / \AA$ & 1.99 & 2.03 & 1.98 \\
$\mathrm{Mn}-\mathrm{O} / \AA$ & 2.05 & 2.07 & 2.06 \\
$\mathrm{~B}-\mathrm{O} / \AA$ & 1.38 & 1.31 & 1.39 \\
\hline
\end{tabular}

Atomic-scale insight into the defect chemistry of cathode materials is essential to better understand their electrochemical performance. The determination of formation energies of Frenkeland Schottky-type defects in the $\mathrm{Li}_{7} \mathrm{Mn}\left(\mathrm{BO}_{3}\right)_{3}$ compound required the calculation and subsequent combination of a series of isolated point defect (vacancy and interstitial) energies. A general KrögerVink representation of the relevant defect equations is given below:

$$
\begin{gathered}
\text { Li Frenkel: } \mathrm{Li}_{\mathrm{Li}}^{\times} \rightarrow \mathrm{V}_{\mathrm{Li}}^{\prime}+\mathrm{Li}_{\mathrm{i}}^{\bullet} \\
\text { Mn Frenkel: } \mathrm{Mn}_{\mathrm{Mn}}^{\times} \rightarrow \mathrm{V}_{\mathrm{Mn}}^{\prime \prime}+\mathrm{Mn}_{\mathrm{i}}^{\bullet \bullet} \\
\text { Schottky: } 7 \mathrm{Li}_{\mathrm{Li}}^{\times}+\mathrm{Mn}_{\mathrm{Mn}}^{\times}+3 \mathrm{~B}_{\mathrm{B}}^{\times}+9 \mathrm{O}_{\mathrm{O}}^{\times} \\
\rightarrow 7 \mathrm{~V}_{\mathrm{Li}}^{\prime}+\mathrm{V}_{\mathrm{Mn}}^{\prime \prime}+3 \mathrm{~V}_{\mathrm{B}}^{\prime \prime \prime}+9 \mathrm{~V}_{\mathrm{O}}^{\bullet \bullet}+\mathrm{Li}_{7} \mathrm{Mn}\left(\mathrm{BO}_{3}\right)_{3}
\end{gathered}
$$

In addition, the $\mathrm{Li} / \mathrm{Mn}$ "anti-site" pair defect was investigated, which involves a $\mathrm{Li}^{+}$ion (radius $0.76 \AA$ ) and a $\mathrm{Mn}^{2+}$ ion (radius $0.83 \AA$ ) exchanging positions, according to:

$$
\text { Li/Mn anti-site: } \mathrm{Li}_{\mathrm{Li}}^{\times}+\mathrm{Mn}_{\mathrm{Mn}}^{\times} \rightarrow \mathrm{Li}_{\mathrm{Mn}}^{\prime}+\mathrm{Mn}_{\mathrm{Li}}^{\bullet}
$$

This type of defect is worth considering because $\mathrm{Li} / \mathrm{M}$ anti-site or cation exchange effects have been observed in other polyanionic materials such as $\mathrm{LiFePO}_{4} \cdot{ }^{28}$ Such disorder can inhibit long-range lithium migration in systems with low dimensional lithium-ion diffusion.

The formation energies of all these types of intrinsic defects are presented in Table 3, from which several conclusions can be drawn. First, the high energies associated with the occurrence of Mn Frenkel and Schottky defects suggest that such intrinsic disorder is not significant in this system. Second, the most favourable types of defect in $\mathrm{Li}_{7} \mathrm{Mn}\left(\mathrm{BO}_{3}\right)_{3}$ are predicted to be the $\mathrm{Li} / \mathrm{Mn}$ anti-site pair and Li Frenkel disorder, with the low energy of the cation intersite exchange being in line with calculations in an earlier study of $\mathrm{LiFePO}_{4}{ }^{28}$ The concentration of anti-site disorder would be temperature sensitive and consequently depend on experimental synthesis conditions. Finally, the low formation

Table 3 Energies of intrinsic defects in $\mathrm{Li}_{7} \mathrm{Mn}\left(\mathrm{BO}_{3}\right)_{3}$

\begin{tabular}{llc}
\hline Disorder type & Eqn & Energy/eV \\
\hline Li Frenkel & $(3)$ & 0.35 \\
Mn Frenkel & $(4)$ & 2.05 \\
Schottky & $(5)$ & 51.02 \\
Li/Mn anti-site & $(6)$ & 0.44
\end{tabular}

energies of lithium interstitial defects indicate a certain degree of flexibility of the lithium framework, which is an interesting property for an intercalation system.

\subsection{Mn redox activity}

Stable $\mathrm{Mn}^{\mathrm{V}}$ oxides are relatively rare. Examples include $\mathrm{Li}_{3} \mathrm{MnO}_{4},{ }^{57,58}$ $\mathrm{Ba}_{3} \mathrm{Mn}_{2} \mathrm{O}_{8},{ }^{59}$ brownmillerite ${ }^{60} \mathrm{Ba}_{2} \mathrm{In}_{2-x} \mathrm{Mn}_{x} \mathrm{O}_{5-x}$ and a number of Mn-doped apatite and spodiosite arsenates, phosphates and vanadates. ${ }^{61-64}$ In all these compounds a tetrahedral $\mathrm{MnO}_{4}{ }^{3-}$ coordination environment is observed. One rationale behind this is that the small size of the $\mathrm{Mn}^{\mathrm{V}}$ ion (ionic radius $0.47 \AA$ ) makes octahedral coordination unfavourable. From ligand field theory ${ }^{58,63}$ it is known that coordination has a strong influence on the redox chemistry. The $t_{2}$ and e energy levels of the d-orbitals in tetrahedral coordination are high in energy and closely spaced. Oxidation from $\mathrm{Mn}^{4+}$ to $\mathrm{Mn}^{5+}$ can occur almost as readily as oxidation from $\mathrm{Mn}^{3+}$ to $\mathrm{Mn}^{4+}$. By contrast, in octahedral coordination, the $e_{g}$ and $t_{2 g}$ orbitals are lower in energy and more widely spaced. Significant energy is required to oxidise $\mathrm{Mn}^{4+}$ to form octahedrally coordinated $\mathrm{Mn}^{5+}$. For this reason there are no stable $\mathrm{Mn}^{\mathrm{V}}$ oxides reported with manganese in octahedral coordination. For battery applications this suggests that to reach higher oxidation states of manganese, and hence higher capacities, the parent structure must contain tetrahedrally coordinated manganese prior to lithium extraction.

Such a tetrahedral Mn coordination environment is found in $\mathrm{Li}_{7} \mathrm{Mn}\left(\mathrm{BO}_{3}\right)_{3}$ and it facilitates the oxidation of manganese from $\mathrm{Mn}^{\mathrm{II}}$ up to $\mathrm{Mn}^{\mathrm{V}}$. The first charge capacity has been reported as $\sim 280 \mathrm{~mA} \mathrm{~h} \mathrm{~g}^{-1}$, corresponding to the removal of around three lithium ions per formula unit. ${ }^{27}$

A key issue in transition metal redox chemistry is "redox stress": as the transition metal is oxidised the transition metal to oxygen bonds shorten and introduce stress into the structure which can cause severe distortion. It was suggested ${ }^{27}$ that in $\mathrm{Li}_{4} \mathrm{Mn}\left(\mathrm{BO}_{3}\right)_{3}$ the $\mathrm{Mn}$ oxidation states as high as +5 may be stabilised by the borate network compensating for redox stress. To investigate this unusual redox activity, ab initio DFT calculations were carried out on both the lithiated and delithiated structures. The calculated and experimental unit cell parameters and mean bond lengths of the lithiated structure are given in Table 2 and show good agreement with experiment, with differences within $0.8 \%$ of experiment.

Using the computed total energies of both the lithiated and the delithiated structures, it is possible to calculate the voltage for the following reaction (employing eqn (2)):

$$
\mathrm{Li}_{7} \mathrm{Mn}^{\mathrm{II}}\left(\mathrm{BO}_{3}\right)_{3} \rightarrow \mathrm{Li}_{4} \mathrm{Mn}^{\mathrm{V}}\left(\mathrm{BO}_{3}\right)_{3}+3 \mathrm{Li}^{+}
$$

The calculated cell voltage of $4.1 \mathrm{~V}$ is in excellent agreement with the experimentally observed average voltage during first charge $(\approx 4 \mathrm{~V}){ }^{27}$ Furthermore, analysis of the electronic structure reveals that on lithium extraction the spin on each $\mathrm{Mn}$ atom decreases from 5 to 2 , indicating $\mathrm{a} \mathrm{d}^{5}-\mathrm{d}^{2}$ transition corresponding to oxidation from $\mathrm{Mn}^{\mathrm{II}}$ to $\mathrm{Mn}^{\mathrm{V}}$. These results suggest two important features: (i) the as-synthesised bulk structure remains in place during the first cycle. (ii) on the first cycle the +5 oxidation state of $\mathrm{Mn}$ is obtained. 
Table 4 Calculated (DFT) $\mathrm{B}-\mathrm{O}$ and $\mathrm{Mn}-\mathrm{O}$ mean bond lengths, and Baur distortion of the $\mathrm{BO}_{3}$ units in $\mathrm{Li} 7 \mathrm{Mn}\left(\mathrm{BO}_{3}\right)_{3}$ and delithiated $\mathrm{Li}_{4} \mathrm{Mn}\left(\mathrm{BO}_{3}\right)_{3}$

\begin{tabular}{|c|c|c|c|}
\hline Compound & $\begin{array}{l}\text { Mean B-O } \\
\text { bond length/Å }\end{array}$ & $\begin{array}{l}\text { Mean Mn-O } \\
\text { bond length/Å }\end{array}$ & $\begin{array}{l}\text { B-O distortion } \\
\text { coefficient } \times 10^{-2}\end{array}$ \\
\hline $\mathrm{Li}_{7} \mathrm{Mn}\left(\mathrm{BO}_{3}\right)_{3}$ & 1.39 & 2.06 & 1.2 \\
\hline $\mathrm{Li}_{4} \mathrm{Mn}\left(\mathrm{BO}_{3}\right)_{3}$ & 1.39 & 1.95 & 5.3 \\
\hline
\end{tabular}

To further understand the stabilisation of such an unusually high redox state, the DFT structural data was analysed. It has been suggested that distortions within the $\mathrm{BO}_{3}$ framework could be present to accommodate the redox stress. ${ }^{27}$ To examine this, the Baur distortion coefficient ${ }^{65}$

$$
D=\frac{1}{n} \sum_{i=1}^{n} \frac{\left|l_{i}-l_{\mathrm{m}}\right|}{l_{\mathrm{m}}}
$$

was computed. Here, $l_{i}$ is the distance from the central atom to the $i$ th coordinating atom, and $l_{\mathrm{m}}$ is the mean bond length to $n$ coordinating atoms. The data in Table 4 shows that upon delithiation, a number of $\mathrm{BO}_{3}$ units experience strong distortions whilst keeping their trigonal-planar shape. This combination of distortion and tilting within the borate framework seems to help accommodate the redox stress.

The changes in the Mn polyhedra are also important. In most polyanionic systems, oxidation of the transition metal leads to large contractions of the $\mathrm{M}-\mathrm{O}$ bonds $(\mathrm{M}=\mathrm{Fe}, \mathrm{Mn}$, $\mathrm{Co}$, $\mathrm{Ni})$. For example, in the $\mathrm{Li}_{2} \mathrm{Mn}\left(\mathrm{SO}_{4}\right)_{2}$ material the $\mathrm{Mn}-\mathrm{O}$ mean bond length in the $\mathrm{MnO}_{6}$ octahedra decreases by $\approx 7 \%$ during oxidation from $\mathrm{Mn}^{\mathrm{II}}$ to $\mathrm{Mn}^{\mathrm{III}} .{ }^{33}$ Here, the mean bond length contracts by $\approx 5 \%$ during much greater oxidation, from $\mathrm{Mn}^{\mathrm{II}}$ to $\mathrm{Mn}^{\mathrm{V}}$ (Table 4). This suggests that less stress is introduced into the system upon oxidation of tetrahedrally coordinated Mn. However, there are major changes to the Mn coordination as lithium is removed and the $\mathrm{BO}_{3}$ units tilt and rotate. The result is that half of the Mn polyhedra become square pyramidal or trigonal bipyramidal (delithiated structure presented in Fig. 2). This has a significant effect on the electronic structure. To illustrate this, the electronic density of states (DOS) has been computed and is presented in Fig. 3. For $\mathrm{Li}_{7} \mathrm{Mn}\left(\mathrm{BO}_{3}\right)_{3}$ the DOS contains a large band gap of around $5 \mathrm{eV}$, consistent with the known insulating behaviour and as expected for a tetrahedral crystal field splitting. In $\mathrm{Li}_{4} \mathrm{Mn}\left(\mathrm{BO}_{3}\right)_{3}$, however, the band gap is not present since the unoccupied d-states are shifted up in energy. The change in coordination from tetrahedral to pyramidal thus removes the crystal field splitting. An interesting consequence of this is that $\mathrm{Li}_{7} \mathrm{Mn}\left(\mathrm{BO}_{3}\right)_{3}$ is predicted to change from electronically insulating to (semi)-metallic on delithiation to form $\mathrm{Li}_{4} \mathrm{Mn}\left(\mathrm{BO}_{3}\right)_{3}$.

These significant coordination changes in the Mn polyhedra could partly explain the capacity loss of almost $50 \%$ reported after the first cycle ${ }^{27}$ since they may prevent the structure from re-admitting all lithium ions upon discharge. A number of other factors could also cause the capacity fade, including structural disintegration, amorphisation and thermal decomposition via the release of $\mathrm{O}_{2}$. For example, recent work by Ceder $e t$ al. ${ }^{66}$ has suggested that in transition metal borates the temperature at which $\mathrm{O}_{2}$ is released drops from around $500{ }^{\circ} \mathrm{C}$ for transition

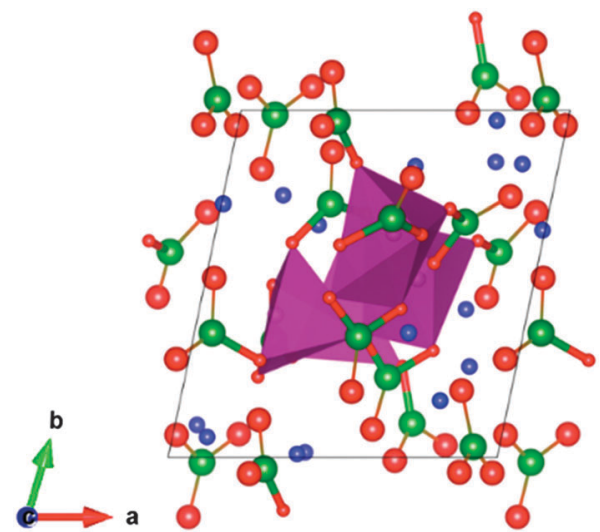

Fig. 2 Calculated (DFT) delithiated crystal structure of $\mathrm{Li}_{4} \mathrm{Mn}\left(\mathrm{BO}_{3}\right)_{3}$ seen along [001]; key: O-red, B-green, Li-blue, Mn polyhedra-violet.

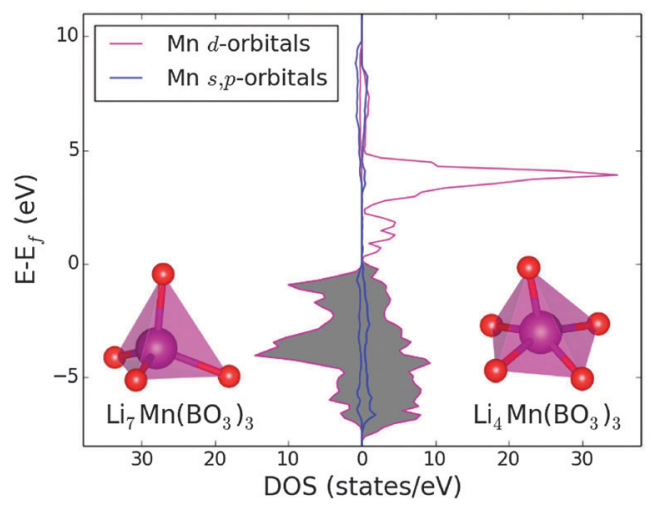

Fig. 3 Manganese electronic density of states in $\mathrm{Li}_{7} \mathrm{Mn}\left(\mathrm{BO}_{3}\right)_{3}$ (left) and $\mathrm{Li}_{4} \mathrm{Mn}\left(\mathrm{BO}_{3}\right)_{3}$ (right).

metals in a +3 oxidation state to around $250{ }^{\circ} \mathrm{C}$ for transition metals in a +4 oxidation state. It seems likely that for $\mathrm{Mn}^{\mathrm{V}}$ the $\mathrm{O}_{2}$ release temperature could be even lower, perhaps within the typical operating temperature of the battery, which warrants further study as well as possible disproportionation ${ }^{57}$ of $\mathrm{Mn}^{\mathrm{V}}$ into other oxidation states.

To summarise, although it is difficult to isolate the impact of individual structural features upon the voltage, it would seem that the initial tetrahedral coordination of $\mathrm{Mn}$ together with the distortion and tilting offered by the $\mathrm{BO}_{3}$ units both act to minimise the redox stress and allow for higher Mn oxidation states to be stabilised; this allows more lithium to be extracted and higher electrode capacities to be reached. However, changes in the Mn coordination environment may inhibit subsequent lithium intercalation, in line with the dramatic capacity loss observed on first discharge. ${ }^{27}$

\subsection{Lithium-ion diffusion}

Knowledge of Li-ion transport properties is vital for a better understanding of electrode kinetics in potential cathode materials. In this study, $\mathrm{MD}$ calculations over long simulation time scales were performed for the $\mathrm{Li}_{7} \mathrm{Mn}\left(\mathrm{BO}_{3}\right)_{3}$ system for a range of temperatures. 


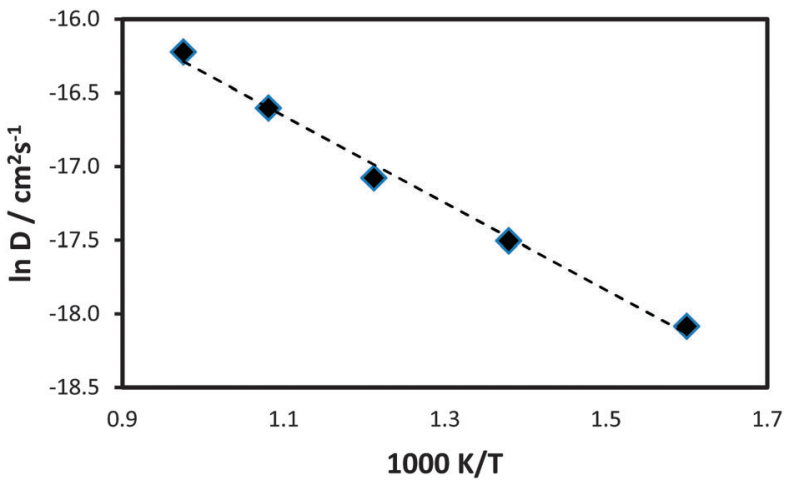

Fig. 4 Arrhenius plot of the lithium diffusion coefficient $(D)$ for $\mathrm{Li}_{6.3} \mathrm{Mn}\left(\mathrm{BO}_{3}\right)_{3}$.

First, the mean squared displacements (MSDs), $\left\langle[r(t)]^{2}\right\rangle$, of lithium ions have been calculated. Examples of these are presented in Fig. S1 (ESI $\dagger$ ) and indicate significant lithium-ion diffusion in this system. The lithium ion diffusion coefficient $\left(D_{\mathrm{Li}}\right)$ was determined from the MSD data for a number of different temperatures. There is currently no experimental conductivity data available for this system. However, the calculated $D_{\mathrm{Li}}$ value, of the order of $10^{-9} \mathrm{~cm}^{2} \mathrm{~s}^{-1}$ at $325 \mathrm{~K}$, is in agreement with other electrode materials, such as the conventional cathode $\mathrm{LiCoO}_{2}$ and its solid solution derivative $\mathrm{Li}(\mathrm{Ni}, \mathrm{Mn}, \mathrm{Co}) \mathrm{O}_{2}$, for which experimental lithium diffusion coefficients between $10^{-11}$ and $10^{-8} \mathrm{~cm}^{2} \mathrm{~s}^{-1}$ have been reported for comparable temperatures. $^{67-70}$

The data is presented as an Arrhenius plot $(\ln D$ vs. $1 / T)$ in Fig. 4, from which an estimation of the migration activation energy $\left(E_{\text {act }}\right)$ can be derived. The resulting activation energy of $0.25 \mathrm{eV}$ suggests considerable Li-ion mobility in this system, which is in line with its good rate capability found by experimental investigations. ${ }^{27}$

A key property of any electrode material is the dimensionality of lithium diffusion. Systems with lithium movement constrained to $1 \mathrm{D}$ channels often need careful control of particle morphology to reduce the influence of blocking defects on the electrode rate capability and systems with $3 \mathrm{D}$ lithium migration offer advantages. Scatter or density plots of the locations of $\mathrm{Li}$ ions during MD simulations are a powerful tool to visualize the most frequently traversed trajectories inside the lattice. Density plots of a section of the simulation cell are shown in Fig. 5. The diffuse distribution of lithium ion positions, overlapping to form a coherent network of migration paths expanding in all three dimensions, indicates the presence of 3D lithium diffusion in the $\mathrm{Li}_{7} \mathrm{Mn}\left(\mathrm{BO}_{3}\right)_{3}$ cathode material. Observation of the lithium motion in $\mathrm{Li}_{7} \mathrm{Mn}\left(\mathrm{BO}_{3}\right)_{3}$ reveals that the diffusion is cooperative whereby the motion of one lithium ion affects nearby ions causing several ions to move in each event, which might be a consequence of the high lithium density in this material. Finally, as noted, $\mathrm{Li} / \mathrm{Mn}$ anti-site pairs are expected to be present in the compound. These anti-site defects are not expected to significantly inhibit long-range lithium migration since the 3D network of diffusion trajectories allows lithium ions to bypass "blocked" migration pathways and substantially
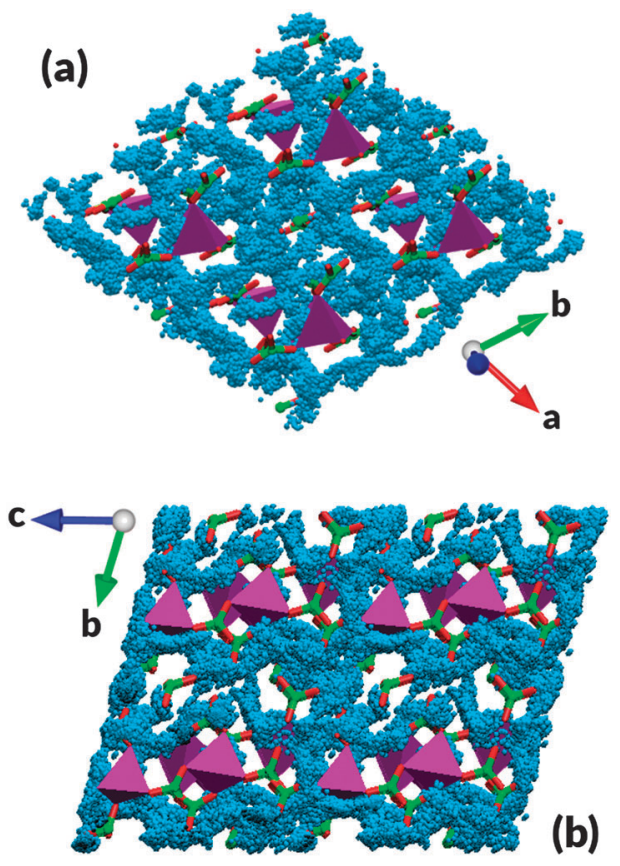

Fig. 5 Lithium density plots from MD of a section of the supercell - in (a) seen along [001] and in (b) along [100] - with migrating lithium ions (blue) visualised superimposed over the initial configuration of $\mathrm{Li} 7 \mathrm{Mn}_{(}\left(\mathrm{BO}_{3}\right)_{3}$, indicating 3D lithium diffusion. Key: tetrahedral $\mathrm{MnO}_{4}$ (violet), trigonal $\mathrm{BO}_{3}$ (green).

diminishes the impact of such disorder on the electrode's rate capability.

\section{Conclusions}

This study of the Li-rich battery material $\mathrm{Li}_{7} \mathrm{Mn}\left(\mathrm{BO}_{3}\right)_{3}$ has employed well-established atomistic simulation and DFT techniques to provide deeper fundamental insight into the defect and redox chemistry, and the mechanisms of lithium diffusion. The main findings can be summarized as follows:

(1) A new interatomic potential model successfully reproduces the observed complex structure of $\mathrm{Li}_{7} \mathrm{Mn}\left(\mathrm{BO}_{3}\right)_{3}$ with its unusual tetrahedral $\mathrm{Mn}^{2+}$ coordination. The most favourable intrinsic defects are $\mathrm{Li} / \mathrm{Mn}$ anti-site pairs, where $\mathrm{Li}^{+}$and $\mathrm{Mn}^{2+}$ ions exchange positions, and Li Frenkel disorder, indicating a certain degree of flexibility of the lithium framework. The degree of disorder would be sensitive to synthesis conditions and thermal history.

(2) Molecular dynamics (MD) simulations reveal a low migration activation energy $(\approx 0.25 \mathrm{eV})$ and $3 \mathrm{D}$ lithium diffusion. These results are consistent with the good rate capability found by electrochemical measurements. The presence of a coherent 3D network of migration pathways reduces the influence of "channel blocking" anti-site defects.

(3) For the lithium extraction process from $\mathrm{Li}_{7} \mathrm{Mn}\left(\mathrm{BO}_{3}\right)_{3}$ to $\mathrm{Li}_{4} \mathrm{Mn}\left(\mathrm{BO}_{3}\right)_{3}$ DFT calculations derive a cell voltage of $4.1 \mathrm{~V}$, in good agreement with the experimental voltage during first charge $(\approx 4 \mathrm{~V})$. The results indicate the activation of the unusual $\mathrm{Mn}^{\mathrm{V}}$ redox state. On lithium extraction to form $\mathrm{Li}_{4} \mathrm{Mn}\left(\mathrm{BO}_{3}\right)_{3}$ a $5 \%$ 
contraction of the $\mathrm{Mn}-\mathrm{O}$ bonds is found, together with distortion and tilting of the $\mathrm{BO}_{3}$ units, which relieves the redox stress and allows the higher oxidation state (and higher capacity) to be reached. However, during this lithium extraction, half of the Mn tetrahedra become square pyramidal or trigonal bipyramidal; these structural rearrangements may impede subsequent insertion of lithium back into the structure and could be the cause of the significant capacity loss observed after the first cycle.

\section{Acknowledgements}

We thank the EPSRC (programme grant EP/K016288/1), the MCC/Archer consortium (EP/L000202) and the ERASMUS scheme for supporting this work.

\section{References}

1 M. Armand and J. M. Tarascon, Nature, 2008, 451, 652.

2 J. B. Goodenough and Y. Kim, Chem. Mater., 2010, 22, 587.

3 B. L. Ellis, K. T. Lee and L. F. Nazar, Chem. Mater., 2010, 22, 691.

4 M. S. Islam and C. A. Fisher, Chem. Soc. Rev., 2014, 43, 185. 5 C. Masquelier and L. Croguennec, Chem. Rev., 2013, 113, 6552.

6 V. Etacheri, R. Marom, R. Elazari, G. Salitra and D. Aurbach, Energy Environ. Sci., 2011, 4, 3243.

7 A. K. Padhi, K. S. Nanjundaswamy and J. B. Goodenough, J. Electrochem. Soc., 1997, 144, 1188.

8 A. Nyten, A. Abouimrane, M. Armand, T. Gustafsson and J. O. Thomas, Electrochem. Commun., 2005, 7, 156.

9 M. S. Islam, R. Dominko, C. Masquelier, C. Sirisopanaporn, A. R. Armstrong and P. G. Bruce, J. Mater. Chem., 2011, 21, 9811.

10 N. Recham, J. N. Chotard, L. Dupont, C. Delacourt, W. Walker, M. Armand and J. M. Tarascon, Nat. Mater., 2010, 9, 68.

11 R. Tripathi, T. N. Ramesh, B. L. Ellis and L. F. Nazar, Angew. Chem., Int. Ed., 2010, 49, 8738.

12 G. Rousse and J. M. Tarascon, Chem. Mater., 2014, 26, 394.

13 B. L. Ellis, W. R. M. Makahnouk, Y. Makimura, K. Toghill and L. F. Nazar, Nat. Mater., 2007, 6, 749.

14 S. Nishimura, M. Nakamura, R. Natsui and A. Yamada, J. Am. Chem. Soc., 2010, 132, 13596.

15 M. Reynaud, M. Ati, B. C. Melot, M. T. Sougrati, G. Rousse, J. N. Chotard and J. M. Tarascon, Electrochem. Commun., 2012, 21, 77.

16 J. M. Clark, C. Eames, M. Reynaud, G. Rousse, J. N. Chotard, J. M. Tarascon and M. S. Islam, J. Mater. Chem. A, 2014, 2, 7446.

17 A. Yamada, N. Iwane, Y. Harada, S. Nishimura, Y. Koyama and I. Tanaka, Adv. Mater., 2010, 22, 3583.

18 V. Legagneur, Y. An, A. Mosbah, R. Portal, A. Le Gal La Salle, A. Verbaere, D. Guyomard and Y. Piffard, Solid State Ionics, 2001, 139, 37.

19 A. Abouimrane, M. Armand and N. Ravet, Proc. - Electrochem. Soc., 2003, 20, 15.
20 L. Chen, Y. Zhao, X. An, J. Liu, Y. Dong, Y. Chen and Q. Kuang, J. Alloys Compd., 2010, 494, 415.

21 J. C. Kim, C. J. Moore, B. Kang, G. Hautler, A. Jain and G. Ceder, J. Electrochem. Soc., 2011, 158, A309.

22 Y. Janssen, D. S. Middlemiss, S. H. Bo, C. P. Grey and P. G. Khalifah, J. Am. Chem. Soc., 2012, 134, 12516.

23 S. Afyon, D. Kundu, F. Krumeich and R. Nesper, J. Power Sources, 2013, 224, 145.

24 L. Tao, G. Rousse, J. N. Chotard, L. Dupont, S. Bruyère, D. Hanzel, G. Mali, R. Dominko, S. Levasseur and C. Masquelier, J. Mater. Chem. A, 2014, 2, 2060.

25 Y. S. Lee and H. Lee, Electron. Mater. Lett., 2014, 10, 253.

26 K. Mizushima, P. C. Jones, P. J. Wiseman and J. B. Goodenough, Mater. Res. Bull., 1980, 15, 783.

27 S. Afyon, M. Wörle and R. Nesper, Angew. Chem., Int. Ed., 2013, 52, 12541.

28 M. S. Islam, D. J. Driscoll, C. A. J. Fisher and P. R. Slater, Chem. Mater., 2005, 17, 5085.

29 A. R. Armstrong, N. Kuganathan, M. S. Islam and P. G. Bruce, J. Am. Chem. Soc., 2011, 133, 13031.

30 A. Whiteside, C. A. J. Fisher, S. C. Parker and M. S. Islam, Phys. Chem. Chem. Phys., 2014, 16, 21788.

31 C. Eames, A. R. Armstrong, P. G. Bruce and M. S. Islam, Chem. Mater., 2012, 24, 2155.

32 F. Zhou, M. Cococcioni, C. A. Marianetti, D. Morgan and G. Ceder, Phys. Rev. B: Condens. Matter Mater. Phys., 2004, 70, 23.

33 C. Eames, J. M. Clark, G. Rousse, J.-M. Tarascon and M. S. Islam, Chem. Mater., 2014, 26, 3672.

34 A. R. Armstrong, C. Lyness, P. M. Panchmatia, M. S. Islam and P. G. Bruce, Nat. Mater., 2011, 10, 223.

35 C. Eames and M. S. Islam, J. Am. Chem. Soc., 2014, 136, 16270.

36 A. Walsh, A. A. Sokol and C. R. A. Catlow, Computational Approaches to Energy Materials, Wiley-Blackwell, 2013.

37 W. Koch and M. C. Holthausen, A Chemist's Guide to Density Functional Theory, Wiley-VCH Verlag GmbH, Weinheim, 2001.

38 J. D. Gale and A. L. Rohl, Mol. Simul., 2003, 29, 291.

39 C. R. A. Catlow, Computer Modelling, Inorganic Crystallography, Academic Press, San Diego, 1997.

40 W. Smith and T. R. Forester, J. Mol. Graphics, 1996, 14, 136. 41 H. J. C. Berendsen, J. P. M. Postma, W. F. van Gunsteren, A. DiNola and J. R. Haak, J. Chem. Phys., 1984, 81, 3684.

42 S. Lee and S. S. Park, J. Phys. Chem. C, 2012, 116, 6486.

43 C. Tealdi, C. Spreafico and P. Mustarelli, J. Mater. Chem., 2012, 22, 24870.

44 S. Adams and R. P. Rao, Solid State Ionics, 2011, 184, 57.

45 M. Vijayakumar, S. Kerisit, K. M. Rosso, S. D. Burton, J. A. Sears, Z. Yang, G. L. Graff, J. Liu and J. Hu, J. Power Sources, 2011, 196, 2211.

46 S. E. Boulfelfel, G. Seifert and S. Leoni, J. Mater. Chem., 2011, 21, 16365.

47 M. Salanne, M. Marrocchelli and G. W. Watson, J. Phys. Chem. C, 2012, 116, 18618.

48 P. M. Panchmatia, A. R. Armstrong, P. G. Bruce and M. S. Islam, Phys. Chem. Chem. Phys., 2014, 16, 21114. 
49 M. Schroeder, C. Eames, D. A. Tompsett, G. Lieser and M. S. Islam, Phys. Chem. Chem. Phys., 2013, 15, 20473.

50 A. Chroneos, D. Parfitt, J. A. Kilner and R. W. Grimes, J. Mater. Chem., 2010, 20, 266.

51 G. Kresse and J. Furthmuller, Phys. Rev. B: Condens. Matter Mater. Phys., 1996, 54, 11169.

52 P. E. Blochl, Phys. Rev. B: Condens. Matter Mater. Phys., 1994, 50, 17953.

53 G. Kresse and D. Joubert, Phys. Rev. B: Condens. Matter Mater. Phys., 1999, 59, 1758.

54 J. P. Perdew, K. Burke and M. Ernzerhof, Phys. Rev. Lett., 1996, 77, 3865.

55 J. P. Perdew, A. Ruzsinszky, G. I. Csonka, O. A. Vydrov, G. E. Scuseria, L. A. Constantin, X. Zhou and K. Burke, Phys. Rev. Lett., 2008, 100, 136406.

56 F. Zhou, M. Cococcioni, C. A. Marianetti, D. Morgan and G. Ceder, Phys. Rev. B: Condens. Matter Mater. Phys., 2004, 70, 235121.

57 G. Meyer and R. Hoppe, Z. Anorg. Allg. Chem., 1976, 424, 249.

58 J. A. Saint, M. M. Doeff and J. Reed, J. Power Sources, 2007, $172,189$.

59 M. T. Weller and S. J. Skinner, Acta Cryst., 1999, C55, 154.
60 P. Jiang, J. Li, A. Ozarowski, A. W. Sleight and M. Subramanian, Inorg. Chem., 2013, 52, 1349.

61 D. A. Grisafe and F. A. Hummel, J. Solid State Chem., 1970, 2, 160.

62 D. Reinen and R. Allman, Z. Anorg. Allg. Chem., 1986, 542, 71.

63 H. Lachwa and D. Reinen, Inorg. Chem., 1989, 8, 1021.

64 M. H. Whitmore, H. R. Verdún and D. J. Singel, Phys. Rev. B: Condens. Matter Mater. Phys., 1993, 47, 11479.

65 W. H. Baur, Acta Crystallogr., Sect. B: Struct. Crystallogr. Cryst. Chem., 1974, 30, 1195.

66 A. Jain, G. Hautier, S. P. Ong, S. Dacek and G. Ceder, Phys. Chem. Chem. Phys., 2015, 17, 5942.

67 Q. S. Wang, J. H. Sun, C. H. Chen and X. M. Zhou, J. Therm. Anal. Calorim., 2008, 92, 563.

68 M. Park, X. Zhang, M. Chung, G. B. Less and A. M. Sastry, J. Power Sources, 2010, 195, 7904.

69 P. Jeevan-Kumar, K. Jayanth-Babu, O. M. Hussain and C. M. Julien, Solid State Ionics, 2013, 19, 47.

70 W. C. West, J. Soler, M. C. Smart, B. V. Ratnakumar, S. Firdosy, V. Ravi, M. S. Anderson, J. Hrbacek, E. S. Lee and A. Manthiram, J. Electrochem. Soc., 2011, 158, A883. 